\title{
The Pandemic PhD programme
}

\section{Reading and thinking about the Celebrity Intellectual (and Covid-19)}

\author{
Tara Brabazon $^{1} \&$ Aidan Cornelius-Bell ${ }^{2} \&$ Elisa Armstrong ${ }^{3}$ \\ ${ }^{1}$ Dean of Graduate Research and the Professor of Cultural Studies, Flinders University, Adelaide, \\ Australia \\ ${ }^{2,3} \mathrm{PhD}$ candidate at Flinders University, Adelaide, Australia \\ Correspondence: Tara Brabazon, Flinders University, Adelaide, Australia. \\ Email: tara.brabazon@flinders.edu.au
}

Doi: 10.23918/ijsses.v8i1p165

\begin{abstract}
This article presents an unusual study of a reading group conducted during the COVID-19 lockdown, shutdown and social isolation. The international collectivity created through this reading community probed not only scholarly monographs but the nature of a celebrity intellectual. As the higher education sector suffers redundancies, cutbacks and restructures, how does the precariat adjunct academy manage the celebrity intellectual and Quit Lit? More importantly, what is the use of academic reading and writing in a PhD programme confronting a pandemic?
\end{abstract}

Keywords: Celebrity Intellectual, Quit Lit, COVID-19, Post-Pandemic University, Pandemic PhD, Academic Literacies, Reading and Writing Cultures

\section{A Stroppy Dean's Introduction (Tara)}

Most days, I summon an irascible diatribe about the state of higher education, teaching, learning, and citizenship. I shake my fist. I roll my eyes. I sigh as if I am a guest star on Bold and the Beautiful. I am angry at a loss of scholarly standards. Behind the anger is fear. Through Brexit and Trump, through riots and \#metoo, through the murder of George Floyd and apologists for colonization, a lack of thinking has been shown to be dangerous to the foundational definitions of public good. For me, there is a triangle that enables education and - indeed - citizenship.

Received: May 25, 2021

Accepted: June 28, 2021

Brabazon, T., Cornelius-Bell, A., \& Elisa Armstrong, E. (2021). The Pandemic PhD programme Reading and Thinking about the Celebrity Intellectual (and Covid-19). International Journal of Social Sciences \& Educational Studies, 8(1), 165-188. 


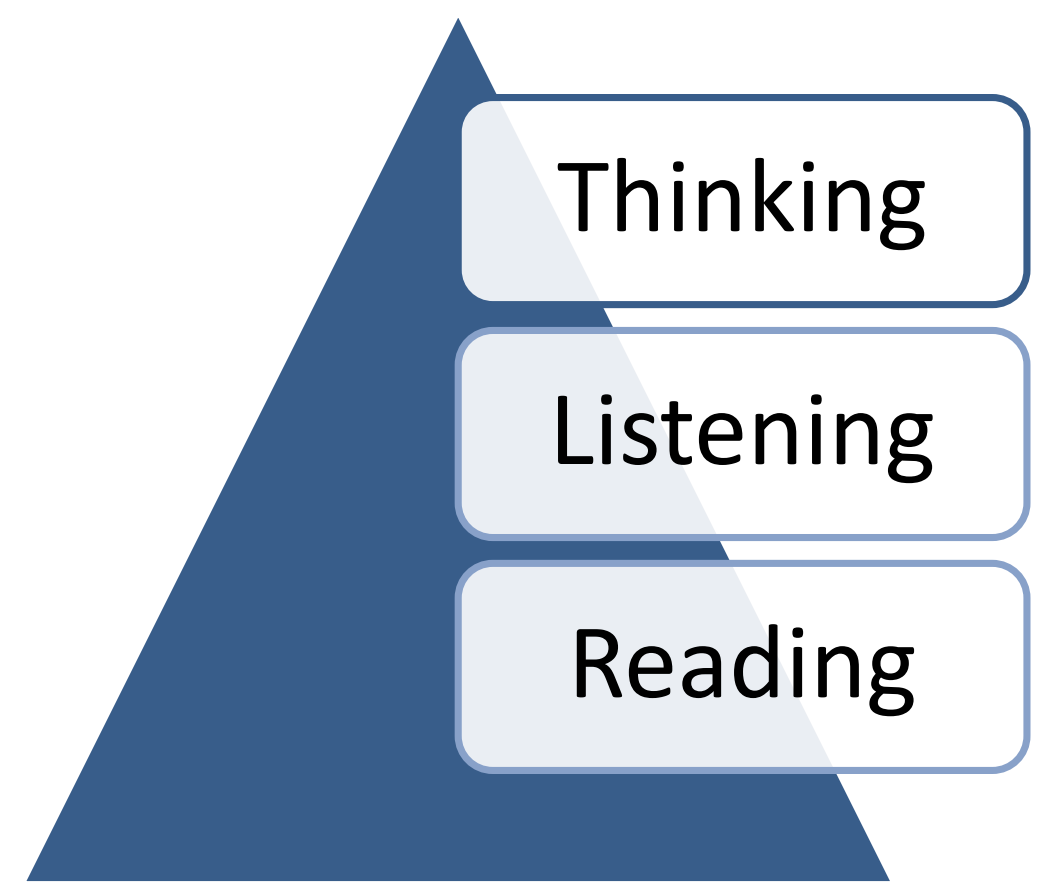

When cascaded and combined, a learning culture can emerge. Yet too often, one or more of these variables is absent. Covid-19 summoned "panic learning" (Brabazon, Quinton and Hunter, 2020). The rush to cutprice and ill-prepared online delivery of content was based on twenty years of under-funded 'innovations' without the attendant commitment to professional development (Brabazon, 2002; Brabazon, 2007; Brabazon, 2013). Disruptive technology became more important than disciplined engagement with ideas.

Digitization has a complex role in this tale of disappointment and worry about scholarly standards. Particularly through the Read Write Web, people with internet access had the capacity to read, engage and interpret ideas far beyond the shelves of the local university library. This expansion was remarkable and provided expansive access to high quality information, alongside low-quality material. But access is not understanding. Access is not information literacy.

The behaviour of researchers was studied in the mid-2000s through this proliferation of information and the lagging information literacy. The results were disturbing. In January 2007, the Joint Information Systems Committee (JISC) published Information behaviour of the researcher of the future. Not surprisingly, the press labelled it the Google Generation Report. The research team tracked the reading behaviour of both students and teachers. The findings of the Report were extraordinary and gave a clear indication of the future in which we now live.

1. All researchers - not only 'young people' - are skim reading research, reading abstracts rather than drilling deeper into the paper.

2. Young people are not 'dumbing down.' Society is 'dumbing down.'

3. "The information literacy of young people has not improved with the widening access to technology" $(2007,12)$. 
4. "Young scholars are using tools that require little skill: they appear satisfied with a very simple or basic form of searching" $(2007,14)$.

5. "Digital literacies and information literacies do not go hand in hand" $(2007,20)$.

The assumptions about digitization as efficient, productive and cheap created a university system where superficial learning, rapid degrees, and rubrics are the punctuation for undergraduate degrees. There is a hanging chad of a question that emerges from this Google Generation Report. What happens to $\mathrm{PhD}$ students emerging from this research culture? Further, through the casualization of the precariat academy, the capacity to provide meaningful feedback is truncated as speed and efficiency, rather than quality and engagement, is valued and funded.

I have been stroppy about the excuses made for low levels of reading, writing and thinking for twenty-five years. This stroppiness is shared by researchers in Critical University Studies. The embodiment of this concern is captured in Arum and Roksa's Academically Adrift (2011a). This remarkable and disturbing book and research confirmed through an empirical, longitudinal study, that students learned very little through a four-year degree. Student reading, writing and interpretative skills were tested when the degree commenced, and when it ended. Very little improvement of any kind was measured. They stated,

We found consistent evidence that many students were not being appropriately challenged. In a typical semester, $50 \%$ of students did not take a single course requiring more than 20 pages of writing, 32\% did not have any classes that required reading more than 40 pages per week, and $36 \%$ reported studying alone five or fewer hours per week. Not surprisingly, given such a widespread lack of academic rigor, about a third of students failed to demonstrate significant gains in critical thinking, complex reasoning and writing ability during their four years of college (2011b).

In my current role, as the Dean of Graduate Research, this result is more troubling, in a deeper way. It suggests that students are under-prepared when they enter a doctoral programme. When required to lift the scope and scale and difficulty of their research and writing, the students are un(der)prepared to make this leap in scholarship. Many proxies for this problem emerge including long candidatures, attrition, complaints about supervision and mental health challenges. None of these attributes are caused by a lack of information literacy, reading and writing, but there is a provocative correlation to explore between the capacity to complete wide ranging and complex reading and the ability to deliver research outcomes.

This is not only a problem of doctoral education or undergraduate degrees. Studies of reading behaviours are attended by such phrases as "secondary orality" or "post-literate culture" (Crain, 2018). More significantly, these two phrases are aligned with a behaviour that 'we' are less likely to spend time with ideas with which we disagree. Indeed, reading in the United States between 2003 and 2016 reduced from 0.36 to 0.29 hours each day (Crain, 2018). This is a consequence of changing class structures. The rich read more, but they are reading less each year. Similarly, the older the American, the more likely they are to read. 
This seems an odd an argument to make in our digital age. 'We' read emails, Facebook posts, Tweets and LinkedIn updates all day. Indeed, most of the world's population did not read until a hundred years ago. Now, reading is part of work. We read to shop. We read to move our bodies through different locations. But reading for sustained periods creates connections. Indeed - and intriguingly - empathy and curiosity are also developed (Damiano, 2019). There is no recognition that those who do not read are aware of those who do. Reading is enlivening. It is also porous. It soaks into writing. Reading allows us to learn from others who have worked hard to research and create an argument. As Michael Hyatt confirmed, "readers are likely to be leaders" (2020). Reading is an efficient way to learn, but also creates habits in gaining information beyond personal experience and to balance evidence to develop arguments.

I complain. A lot. It is more optimistic and indeed more productive to intervene, to transform. Through the changes to universities and the world through COVID-19, I wanted to create a different way of thinking about reading for doctoral candidates, using the capacity of digitization to build community, communication and connection.

\section{Covid Campus Culture (Tara reflects on the strange gifts from disruption)}

Digital disruption was too easily celebrated in the late 1990s. Disruption was carried on a neoliberal wave, signifying benefits and opportunities though being - to summon the cliché of our time - agile. But change is not always beneficial or useful. Disruption can create change, but without context, planning or a recognition that disempowered communities often have the least opportunity to move and change to a new set of working, learning and living 'standards.' When applied to our higher education sector in a study of the impact of Covid-19 on academics, a cascade of words tumbled through their testimony: anxious, worried, stressed, chaotic, unsettled, upheaval, exhausted, tired, challenge (Levine 2021).

Covid-19 was a public health crisis. It was also an educational crisis. It summoned what Gurcan and Kahraman described as "disaster capitalism" (2020). Universities were not in a strong economic or intellectual position going into the pandemic. The rapid transition to online learning meant that an unstable infrastructure toppled. Professional development of academics and students - neglected for decades needed to be triaged as academics who rarely delivered online lectures had to move to this platform within weeks. Research has been and will be impacted for a decade, particularly in allied health. Supervisory / Advisor quality was variable before the pandemic. Once the diversity of stressors emerged, this variability increased, relying more strongly on non-supervisory support (Greener 2021).

My priority as the Dean of Graduate Research was to provide a diversity of peers and a diversity of resources for our students. Just before Australia entered its first lockdown, I conducted a week of Facebook Live sessions (Brabazon 2021). I held a reading group and moved as many synchronous and asynchronous events to the online environment as possible. I continued delivering my weekly vlogs. Certainly, I held many fears. One fear was that students would give up and leave the programme. I knew that Australia held the advantage of being an island, with many of its cities distanced around the continent. Social distancing would be a strong and effective social medication. Therefore, Australian Deans of Graduate Research had a chance to ensure that our universities remained open, if differently organized. But secondly, I was worried that insularity, conformity and inwardness would surface. I wanted to ensure 
that I could use the 3 Ds - digitization, disintermediation and deterritorialization - to use this dreadful time to build new communities and contexts.

Before I commenced as Dean of Graduate Research, I had never heard of Imposter Syndrome. It remained one of the earliest and most urgent requests in my vlog series (Brabazon 2016). It is clear that doctoral studies reveal a higher incidence of depression, anxiety and imposter syndrome than the rest of the population (Pervez 2021). There are many rationales for this list of problematic states. One is that students enter higher education with enthusiasm, passion and motivation, and are then confronted with the reality. Their confidence and hopes collapse. This cascading of emotion was heightened through Covid-19. Understanding doctoral students and their experiences requires an understanding of diversity, and a respect for diverse pathways. There is now a body of research about stress and burnout (Allen 2020). However, a key coping strategy was the development of a social network (Pervez 2021). Peer support created connection without threat and enabled the management of anxiety.

In many ways, I was using digitization, deterritorialization and disintermediation to manage a corporeal crisis. Therefore, I decided to conduct a reading series, based around a single scholar, Sara Ahmed, and to deploy Zoom for these weekly meetings. Indeed, Lisa Parks and Janet Walker described this time and the platforms within it as "Coronavirus media" (2020). I now clear my prose from your screen and welcome my remarkable $\mathrm{PhD}$ student to introduce what happened when a reading group became part of Coronavirus media.

\section{The Set Up - and the Consequences (Elisa's entrée)}

The seminar series sprouted from Tara's suggestion for Aidan and me to read Ahmed's works, and was made necessary by my resistance to actually reading the books my supervisor suggests. When Tara laments that there is not enough reading going on these days - I am the problem. I struggle with academic books. I am an avid reader of fiction, and I will happily read hundreds of pages of articles in a day but if you put a non-fiction book in front of me something inside me breaks. I know that books are important for lots of reasons, but there is a weird mental barrier for me.

I was enthusiastic initially because I felt the seminars would help keep me accountable. The pressure to read one book every week meant that I would stick to it in a way I would not have done if it was a solo endeavour. Of course, the book club morphed into something much greater in scale, reach, and benefit than I could ever have imagined. The inclusion of so many other people who I respect and was worried about embarrassing myself changed the whole dynamic of the project for me.

\section{What's the Use?}

The title of Sara Ahmed's most recent book resonates and echoes through my experiences of the seminar series. It is fair to say I struggled with Ahmed's books, and not gracefully. I sulked and raged at the books I could not seem to understand but felt immense pressure to appreciate. Sara Ahmed is a big deal, a famous academic, and her books are so visible that my parents bought Living a Feminist Life for me from a bookshop when they were on holiday. When I could not make sense of the writing, I took sole responsibility. How could I, someone with a Masters in Women's Studies, not understand her work? I sat, 
staring at my computer screen, pouting and asking myself: "What's the use?" I often felt defeated, not smart enough, and like no matter how hard I tried it just was not going to make sense.

In summary, the seminar series was nine weeks of imposter syndrome; unpleasant but transformative. The first week and the first book really made me question why I was involved at all with the seminar series. We began with Differences That Matter: Feminist Theory and Postmodernism and I could not make sense of it. In my diary, I wrote that the book was "bringing out the petulant child in me" because every time I tried to read a few more pages I had to resist throwing a tantrum. This book embodied everything that I hate about academic writing and theoretical texts. I tried to reread sections, Google key terms for an explanation, I took breaks, drank way too much coffee, and felt that I had made no progress. It was crushing.

I'm feeling like a big imposter because I don't understand the book. I am worried that I will join the discussion on Thursday, and everyone will realise that I am not smart enough to be there.Personal journal entry, week one.

I decided to reach out to Aidan and Tara in the hope that I was not alone in struggling and to get some reassurance. Aidan was kind enough to share his notes with me on the first chapter and it was an enlightening experience. It reinforced my feeling that the book was written in a different language because even in his breakdown of the notes, Aidan was still structuring his thoughts and using words that are foreign to me. It feels like a different way of thinking and explaining the just does not resonate with me. And so, the imposter syndrome was fed.

The first seminar proved crucial for how I managed my imposter syndrome and my difficulty with the subsequent books. I was not the only one who struggled, and it helped me shift my perspective about the problem. Indeed, I was able to start to define the problem. I assumed that because Ahmed is a very wellrespected writer and her books seem popular, that it meant they were of a certain quality and almost beyond reproach from someone like me. Through the reassurance I was not the only one struggling, I was able to shift the entire blame from myself and feel comfortable being critical of how the ideas in the books were explained. I still had to take some responsibility, but I no longer felt like the problem.

Reflecting now, I think from the outset my approach was misguided. I was looking for someone to blame, to be at fault, to hold responsible for a perceived failure. What's the use? Why do I need there to be a wrongdoing? I believe the answer lies in imposter syndrome gatekeeping, and the patriarchal nature of academia. Imposter syndrome affects "individuals from all walks of life" but is most notably observed in "college students and career academics" (Gadsby, 2021, p. 1). It is almost "ubiquitous in higher education" and is oft addressed in advice to fledgling academics (Taylor \& Breeze, 2020, p. 1). Imposter syndrome is "heterogenous: different individuals exhibit it for different reasons - psychology, developmental, and sociocultural" (Gadsby, 2021, p. 2). Imposter syndrome "impedes the growth of a sense of belonging" - a feeling which has been found to being essential to success in higher education (Ramsey \& Brown, 2018). I have always felt like I do not belong at university - a feeling enhanced when I reached postgraduate study. I remember crying early on in my candidature because "people like me don't do PhD's." I felt uncomfortable interacting with other students, as though they could see that I was not enough. Imposter syndrome commonly relates to ability or intelligence, but it can also be about cultural literacies and class 
(Gadsby, 2021, p. 3). Neither of my parents are university graduates, my brother is tradesman, and I come from a background of civil servants and trades. I have always been encouraged to pursue knowledge and my mother used to start debates at the dinner table to challenge us. However, when surrounded by people more familiar with the world of academia and higher education, I feel like a cultural misfit.

Imposter syndrome is typically described as being how an individual perceives their own abilities relative to those around them and the role they are trying to fill. I wonder if imposter syndrome might not be an individualised experience. Might entire disciplines have imposter syndrome? My studies have always been under the umbrella of humanities and social sciences. I have faced much criticism from those around me that my Bachelor of Behavioural Science (Psychology) is not a real science degree. Social sciences are not real science. I always staunchly defended psychology's use of (and rigorous dedication to) the scientific method. I felt a pressure to justify my education as real, important, and valuable by linking it to disciplines that are real. When I explain that my discipline is now cultural studies, I am often asked "what's the use of that?" Disciplines and knowledge are judged by its perceived utility - and it can be harder to get people to appreciate women's studies importance than that of physics or biology. Taylor and Breeze (2020, p. 2) describe feminist academics as being "dismissed as imposters" in universities that are dedicated to disinterested scholarship and more 'objective' knowledgebases. Feminist writing then walks the tightrope of credibility - trying to be respected within patriarchal institutions whilst resisting hegemony. Grey and Sinclair (2006, p. 445) suggest that academic writers outside the sciences might "feel obliged to adopt an equally abstracted vocabulary so as to show that we are, after all, still serious scholars." This is one way to fight imposter syndrome - stressing authenticity, authority, and legitimacy.

Another approach to imposter syndrome is to fight perceptions of legitimacy and genuineness. 'Authentic' is a contrastive term that must stand in opposition to something (Potter, 2010, p. 6). Authenticity is a zerosum game because for something to be authentic renders something else as fake - status cannot be gained without someone else losing (Potter, 2010, p. 119). Academic disciplines exist in a hierarchy - they are able to be continually ranked and re-ranked in different manners (Heinze, 2015, p. 84). At any moment, any individual can rank the various disciplines on different scales using different metrics. Time is also a factor on the resulting ranking. Heterarchies can be considered diachronically as there are elements of "temporality and change" not only to the universe being considered but to the moment that the evaluation occurred (Heinze, 2015, p. 85). It is easier to conform to existing standards of legitimacy and change than it is to radically transform the system. When confronted with my own feelings of illegitimacy and imposter-status in the seminar series, I had to decide how to proceed. I felt that other participants were more articulate, composed, and intelligent than me with my wild hand movements, casual language, and frequent admissions that I had no idea what was going on. ${ }^{1}$

Ahmed described strangers as not being a failure of recognition, but rather being configured through "not belonging, as being out of place" (Ahmed, 2000, p. 21). They are not the unencountered, but someone familiar in their unfamiliarity. These recognitions configure strangers as living in different degrees of strange - some are "stranger than other others" (Ahmed, 2000, p. 25). There becomes a mechanism or

1

I think it is important for me to acknowledge at this point that I do have white privilege, I come from a background where I did not have to worry if there would be dinner on the table, and I can blend into the university if I try hard and need to. 
hierarchy where some people are valued over others, linked to their strangeness or stranger-status (Ahmed, 2000 , p. 30). I feel too strange. Do I conform or resist? I chose to remain apologetically myself but there is a privilege inherent to this. I faced no backlash personally or professionally. It is not always possible to stand apart.

Academic writing does not exist in a bubble, but is part of a "procedure" - part of a "series of connected institutional structures that include large-scale non-profit and corporate entities [...] and formal and informal patterns of practice and habit" (Hayot, 2014, p. 65). Style is one part of these patterns of practice that come together to create disciplinary norms (Hayot, 2014, p. 65). The standard or default style of academic language and writing goes largely unrecognised or critiqued, but it is patriarchal in nature (Pullen \& Rhodes, 2015, p. 88). There is a "normalcy of masculine notions of rigor, hardness, and penetrating conclusiveness" (Kiriakos \& Tienari, 2018, p. 266). Academic publishing, journal ranking and citations force academic writing into moulds, because it is the only way for writers to get published, recognizing the cliché publish or perish. Pullen and Rhodes (2015, p. 88) question these standards to explore how "feminine ontologies, ways of knowing, methodologies" and feminine writing can be encouraged and "flourish." As women remain disadvantaged, "the feminine suffers alongside" and feminine writing might have the potential to contribute to "radical subversion" (Pullen \& Rhodes, 2015, p. 92). Grey and Sinclair (2006, p. 445) suggest that is seems "wrong for a body of writing and theorizing to contribute to the very installation of power relations that it purports to want to overturn." Conforming to patriarchal and masculine forms of writing when they do not suit the writer (or perhaps the work) might then harm and crush the goals of the writer (and the text). There is a need to push the boundaries of what 'academic writing' can look like and how it should be read as part of challenging the hegemonic power structures. I suggest that Ahmed's writing be considered a challenge to the masculine style. There are disciplines such as the experimental sciences and engineering that try to hide or blur the relationship between writer and text to "downplay their personal role" (Hyland, 2002, p. 352). Ahmed presents her writing as being inherently personal - linked to her experiences. I note that the depth of this link in her work is questionable as her work often felt detached from reality for me. I would have liked more anecdotal illustration of experience and examples drawn from reality rather than classical fiction. Part of my resistance to Ahmed's work came from my preconceived ideas of what real academic work looks like. I was introduced to journal articles through formulaic psychology research. I still find the formula of an article comforting because readers can use the abstract, introduction, and conclusion to break through the content when the ideas are challenging. The reassuring familiarity of the formulaic facilitates a level of intellectual laziness. Ahmed's work challenged how I read and how I tackled challenging ideas.

What's the use of academic writing? What purpose does writing and reading these texts serve? Grey and Sinclair (2006, p. 448) ask what is "the point of writing something which only a handful of people can understand?" Grey and Sinclair (2006, p. 445) describe how the "strangulated and pretentious tone of critical management writing" renders it "incapable of speaking to anyone outside a very limited circle" thus reducing its political impact and potentially contributing to alienation and oppression. This applies to work outside of the field of critical management writing - overly complex and hard to navigate texts are not limited to one discipline. There is a pressure to write "formulaic texts laced with jargon that is accessible only to select others" (Kiriakos \& Tienari, 2018, p. 264). When I complained to my partner about how impenetrable the book felt his position was largely "but that is how you lot write, isn't it?" I 
think there is a perception that academic writing (whatever that is) needs to be dense, jargon-rich, and difficult to understand for it to be legitimate. The fewer people that can understand it, then the more complex the theory must be. It serves as a part of academic gatekeeping to an extent because it uses exclusionary tactics to establish credibility. There seems to be an approach to reading that it should "involve suffering" (Grey \& Sinclair, 2006, p. 448), that a headache is necessary for developing an understanding. Legitimacy and the idea of the imposter is once again evoked in these ideas.

What's the use? If the purpose of a text is to share knowledge, and share it widely, then surely it must be understandable. Grey and Sinclair (2006, p. 447) suggest that "complexity of expression often conceals what are quite simple ideas." I found this in my reading of Ahmed's work, where once I muddled through the explanations and examples, the idea seemed quite simple. There can be brilliance in simplicity and often the simple is what goes unsaid, unchallenged, and therefore unaddressed. However, if scholars take a simple idea and wrap it in layers of obscure words and abstract philosophy then they might be doing the idea (and the readers) a disservice. Hayot (2014, p. 67) provides a counterview and suggests that "what some folks call ornamentality communicates and gives pleasure" and rather than simply getting in the way it is. Declaring a text frivolously complex is an aesthetic judgement that claims excessiveness - the same way the body is treated with disgust and described as fat or flabby, so is writing (Hayot, 2014, p. 76). It took me two years to finally (maybe) understand Baudrillard's idea of the simulacrum, so I am not opposed to walking away from a book hugely confused. In my opinion, Ahmed touches on big ideas and has interesting insights, but ultimately fails to push those ideas to their crescendo because she loses momentum and direction. I feel that there is a distinction to note here between the confusion created by complex ideas and that of unclear logical progression. I found myself scratching my head not because Ahmed's ideas were difficult, but because I often could not follow along the story she was telling. I would find myself nodding along and then suddenly I could no longer identify the point that was being made. Grey and Sinclair (2006, p. 452) describe the writing they appreciated as not simply expressing ideas in a "didactic way" but as opening "a door for an experience to be had by a reader", and it should "evoke feelings", "bodily responses", and the "tingle as we feel that this might be showing us something we hadn't thought or experienced before." I live for that tingle. That is what drives me as a person, a thinker, an academic, and a $\mathrm{PhD}$ student. When I read any kind of book, I want to walk away with my brain tingling, my paradigm altered, and excited about the ideas within. I learn best with relatable examples and applied theory - from reality or popular culture. That's why Ahmed's books do not work for me. For others, they do.

There is also a deeply personal purpose to writing. Writing is part of identity - it is "a part of who we are" (Kiriakos \& Tienari, 2018, p. 269). Writing is a reflection of the writer and "almost everything we write says something about us and the sort of relationship that we want to set up with our readers" (Hyland, 2002, p. 352). Writing and the creation of texts is a very personal process which Pullen and Rhodes (2015, p. 92) describe texts as inscribing "themselves on our skin and through our flesh" and being "written by bodies; here, often about bodies." A study by Pittam, Elander, Lusher, Fox, and Payne (2009, p. 159) found that (undergraduate psychology) students found writing to be "more like editing than authoring." Students are taught to weave together references to existing material and similarly, I feel that I was never taught how to integrate my own thoughts, opinions, and understandings. It was not until I reached my $\mathrm{PhD}$ that my supervisor encouraged me to add my thoughts because my ideas mattered too. I was not just to 
regurgitate facts but bring them together to create something new. Somehow, I completed two Bachelors degrees and a Masters (with an 18,000-word thesis) with no voice in my work and no understanding of how I related to my arguments. Finding my voice and learning how to really think and share my ideas has been an incredible struggle. I am learning that there can be an unburdening in writing and sharing experiences. There is a use in Ahmed's books for her. Pondering the complexity of the audience for these books requires greater attention.

What is the use of Ahmed's books? What is the use of academic texts? Perhaps these questions influence our reception of them. An example would be my love of movies like Fast and Furious, The Mechanic, and basically anything with fast cars, fighting, and explosions. I choose to watch these movies because I want to enjoy the cheesy excitement. If someone watched them and wanted an intellectually stimulating and emotionally moving tear-jerker, they would be very disappointed. Neither of us would be inherently wrong in our experience of the movies because our goals were different and therefore the perspective through which the watching occurred was different. How I approach learning and reading at this stage, Ahmed's books are a good choice for pithy and insightful quotes or a flick through for the beginning of ideas. As I reread those notes to write this piece, I realised that this applies to my experience with the books. I became concerned with how to correctly position or orientate myself in relation to the books and the ideas within, rather than questioning the books/ideas as a desired object. Perhaps there is an incompatibility between me and Ahmed's work. Growing, developing, and learning as an academic, a student, or just as a person is like assembling your own galaxy of ideas, texts, and influences. With yourself as the centre, the influential texts, ideas, and people who you learn from begin to populate the galaxy as planets, stars, and celestial bodies. All these entities have an influence, but their orbits might be different strengths and might waver over time - as our relationship with them changes. Not everything fits in our systems - or can be accommodated significantly. Perhaps the ideas that leave a trace but do not remain are still significant. Perhaps Ahmed's work just doesn't fit in my galaxy - but for others it becomes a central planet. The rejection or setting aside of texts that are 'core', 'foundational', or 'required reading' needs to be normalised to resist intellectual stagnation and hegemony.

What is the use of this section of the article? I have tried to explain the use of the seminar series for me. The intention when I began back with Ahmed's first book was to learn - to take away new theory, ideas, and concepts from her work. I am unsure how many ideas I took away from the content of her writing because of a fundamental incompatibility between my context, background and goals, and her work. The real value for me came from reflecting on how I interacted with Ahmed's work. I felt defeated. My reaction was to feel like an imposter and look inwards for a cause. I then rejected her work - the problem was not with me and my understanding, but rather her books were flawed or bad somehow. I began writing this piece from this perspective, focusing on my experiences with imposter syndrome and aiming to criticise Ahmed based on her work being overcomplicated, impenetrable, and useless. Useless, because if I cannot understand a book, then surely that undermines the entire purpose of the book? If I cannot draw facts or theory from a text, sucking them out like a leech, and then embedding them in my next piece of work, then what is the use? Ultimately, Sara Ahmed's work was not ground-breaking and earth shattering to me, or even particularly interesting overall. But it was for some people in the seminar group. That needs to be okay. It needs to be acceptable for some to criticise and some to praise. Readers should be wary of 
uncritically praising the work of 'celebrity intellectuals' (as some might do for Ahmed) and be empowered to resist 'popular' opinion to form their own.

I have come to recognise that the problem might be much bigger than me or Sara Ahmed and her books. Ideas of legitimacy in academia are created and perpetuated by patriarchal institutions. A monolithic knowledge producing engine that marginalises the feminine in favour of spewing out hard sciences, "facts", and formulaic journal articles. Entire disciplines are undermining themselves and crushing alternative research methods, writing styles, and thought to fight their imposter syndrome. Imposter syndrome serves hegemony, it serves the patriarchy, it serves the status quo. By rendering imposter syndrome and the ideas of academic authenticity or legitimacy the problem of the individual, we ignore the wider structure that the individual sits within. Academia must allow for multiplicity. There cannot be a single way that we must all conform to.

\section{Celebrity Intellectuals (where Tara ponders how she reminds Elisa how remarkable she is)}

It is both humbling and worrying for me as a supervisor to read and understand Elisa Armstrong's fears and worries. The spaces encircling a $\mathrm{PhD}$ student are unstable. Volatile. Dynamic. Such fears are placed in an even more stark contrast when configured in relation to the celebrity intellectual culture, of which Sara Ahmed is a part. Elisa Armstrong introduced the celebrity intellectual. Her entrée is the foundation for the next intellectual course.

I remain fascinated by the celebrity intellectual. Or - indeed - the celebrity $\leftrightarrow$ intellectual. The next question is, do either of these words or phrases describe Sara Ahmed? Before I address this question, I have a confession. I own a bespoke, Etsy-created statue of Jean Baudrillard.
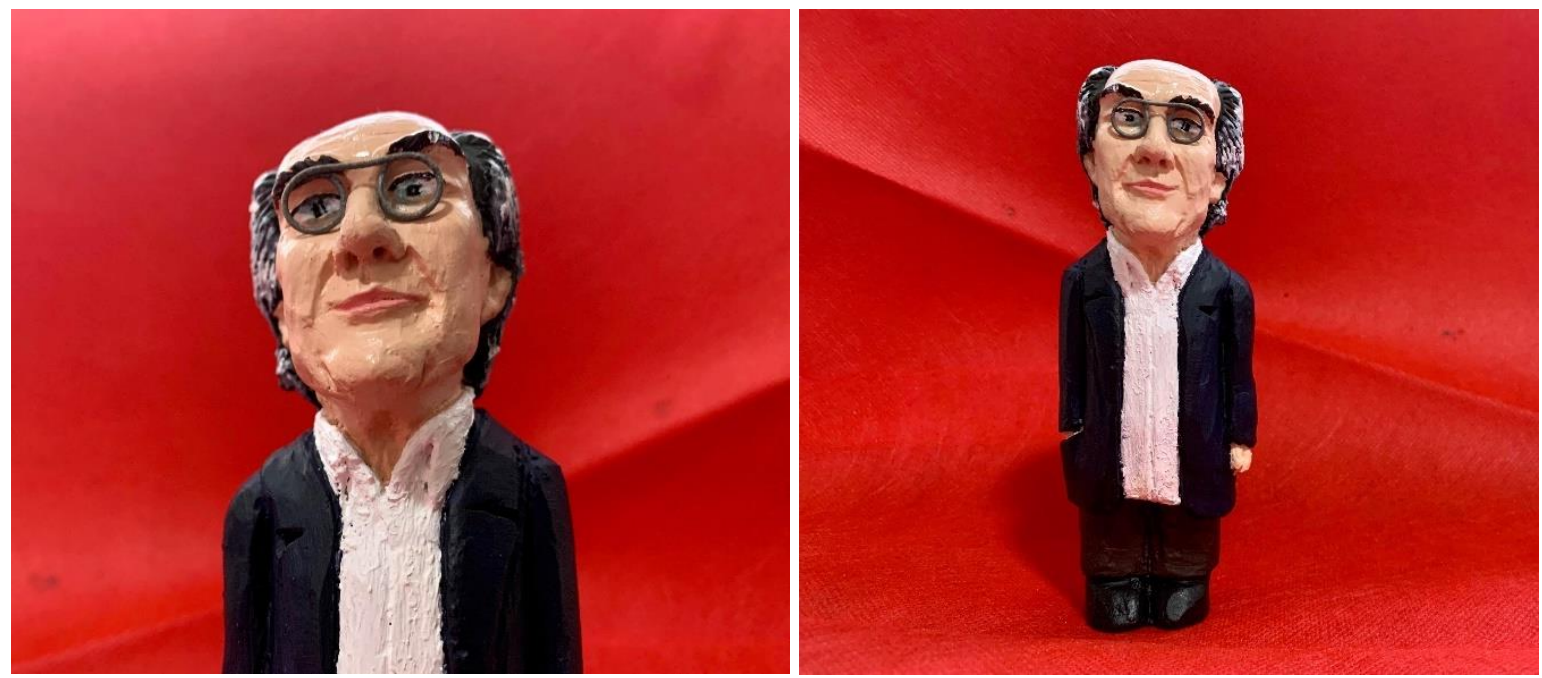

Jean Baudrillard is also featured in the Philosophy Football selection of T-shirts (Philosophy Football 2021). He also has his own puppet. 


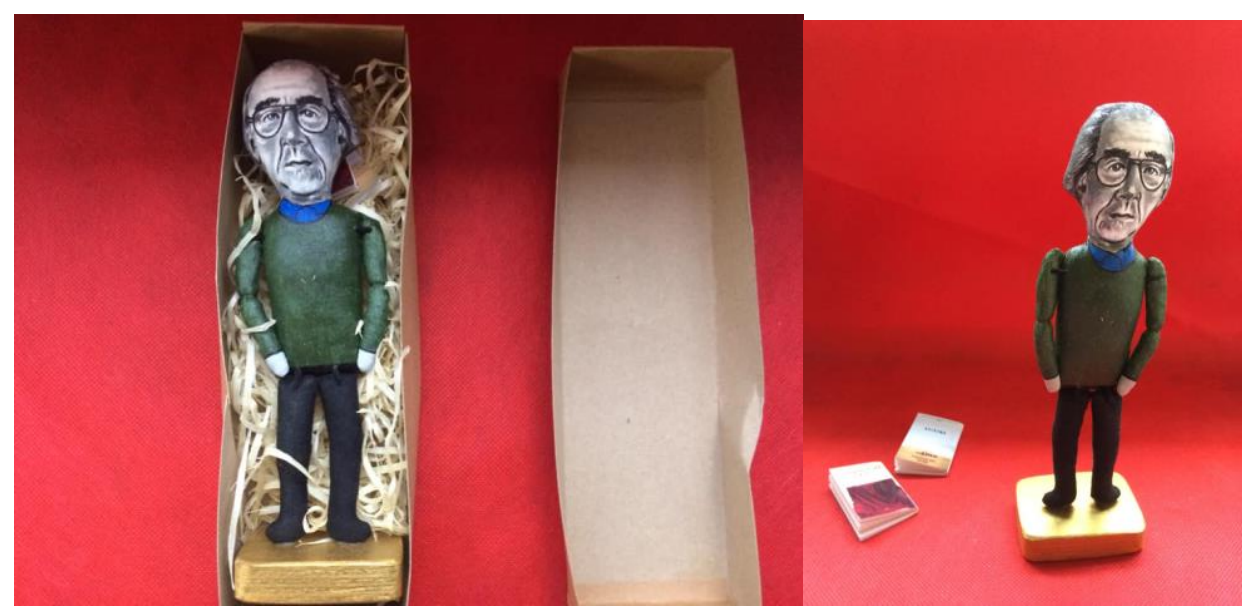

Based in Ukraine, Celebrity with You is a firm that provides unusual products based on 'celebrities' such as Jean Baudrillard. This is fame. I have yet to even mention The Matrix.

French theory and theorists, with whom Sara Ahmed showed great focus as an early career researcher and in her first monograph in particular, has transformed our university life. Jean Baudrillard was mentioned in a popular film series. Jacques Derrida has been the focus of a popular documentary. YouTube features thousands of snippets of Michel Foucault, being pithy, leaning back in his chair, demonstrating arrogant confidence through even Noam Chomsky's best attempts to ask questions. Slavoj Zizek and Jordan Peterson have continued these celebrity intellectual trajectories, albeit in different ways. Both have used YouTube to blistering effect, building a large audience and a loyalty for what are often odd or simply wrong ideas.

In so many ways, the recognition of theory and theorists is welcome. With reified chants of "Believe the Science" punctuating our culture, the capacity to understand the science, with disciplinary literacy, is less important than faith in particular methodologies in secular times. The political and economic commitment to the empirical, and often empiricist, is more troubling. The assumption that qualitative and quantitative methods can provide solutions to social problems is prioritizing methodology over ontology and epistemology.

The 21st Century has revealed the difficulties in confusing the empirical and the empiricist. The Global Financial Crisis, from 2007 to 2008, the ongoing climate crisis with attendant food and energy security concerns, alongside the health and economic consequences of a pandemic has resulted in a confusing and concerning dance between the public and the private. Corporations required a public bailout. Taxpayers bailed out the banks through their search for "fool's gold" (Tett, 2000). Yet this post-catastrophe was not recognized. This "global Keynesianism" was transitory (Blyth 2013). Within months, the bonuses for bankers were back, critiques of regulation continued, and the public bailout for the corruption and lies of private corporations continued. Neo-liberalism was even more cancereal (Mirowski 2013). It is no surprise that with this catastrophe forgotten, marginalized, decentred or ignored, contemporary theorists provided the Dorian Gray portrait in the attic. Theorists did not go away. Theorists did not forget. Our goal was - and is - to create a theory, after theory (Elliott and Aldridge 2011) 
In this post-crash culture, theorists and theorists connected with the fragmented and bruised body politic. It was post-disciplinary. It was fuelled and enabled by open access online journals. These journals focused on Jean Baudrillard, Alain Badiou and Slavoj Zizek. The International Journal of Baudrillard Studies began in 2004. The International Journal of Zizek Studies began in 2007. Badiou Studies started in 2021. Disciplines were not specified or configured as relevant. Political consequences were clear. At the turn of the twenty first century, festering through September 11, the centre right and centre left lost their connected spaces for policy debate. The extreme right, which conflates with the Alt-Right but is composed of complex splinter extreme groups, and the extreme left, which has always been as fragmented as the Life of Brian sketch comedically confirmed, stretched debates into bizarre territory. Small issues became a gateway drug into identity politics. 'Snowflakes' were located. So were 'triggers.' The capacity to create consensus in some form over issues of health, education, working lives and family became increasingly difficult, as policy debates moved to manage these extremes.

Academic disciplines suffered from similar movements. With the death of Baudrillard, Virilio and Bauman, the quirky - often funny - but provocative ideas were lost. Instead, the debate of the decade was between Slavoj Zizek and Jordan Peterson. The topic of this debate was - extraordinarily - happiness. Therefore, the place of academics in this moment of extremism, polarization and opinion substituting for evidence remains unclear (Brabazon, Redhead, Chivaura 2018). It is in this context that Sara Ahmed's academic life and the trajectory of her scholarly monographs must be probed.

Sara Ahmed has lived a life of academic privilege. Being educated at the University of Adelaide, one of the elite Group of Eight Australian Universities, her doctoral research was completed at the Centre for Critical and Cultural Theory at Cardiff University. She was employed from 1994 to 2004 at Lancaster University, then moving to Goldsmiths at the University of London. She resigned from this post in 2016 as a protest over the sexual harassment of students by staff. She has held visiting posts at the University of Adelaide, Rutgers University and Cambridge University. Most of her books are published by Duke University Press, with the others published by Routledge and Cambridge University Press (Ahmed 2017b). After her resignation, she has continued as an independent scholar, blogging and publishing scholarly monographs.

The prefaces of all her books confirm a research academic career of sabbaticals and research leave (Ahmed 1998; Ahmed 2000; Ahmed 2004; Ahmed 2006; Ahmed 2010; Ahmed 2012; Ahmed 2014; Ahmed 2017b; Ahmed 2019). Only one of her books mentions teaching or students. This is an academic career of privilege. Employed by (only) two elite universities from 1994 to 2016 is stark and unusual when considering the precariat university workforce and the scale of the international adjunct academy. I know that the students I graduate from doctoral programmes, including the two co-authors of this article, have no chance of following in her footsteps or managing a stable career of sabbaticals and research leave. Teaching is the blood of the academic body. Research is pinched from an academic life, early in the morning, late at night and on weekends. Therefore, Sara Ahmed has lived an elite academic life, promised to many and lived by few. What is significant is that these elite universities continued the spaces for Women's Studies, Gender Studies and feminism. The requirements for 'employability' and 'graduate attributes' in regional and rural universities, and indeed much of the rest of the sector, is not as urgent or important in these elite universities. 
Noting this career of tenure and privilege, her decision to resign from a stable academic post that is the aspiration of so many $\mathrm{PhD}$ students must be explored. This contradiction - of radical critique while in stable and well-paid academic work - is important to probe in this article and provides a context for much of the confusion, ambiguity and oddities that emerged through the reading group. Carrie Hart and Sarah Colonna asked, inspired by Ahmed, "what does it mean to live a feminist life as a teacher or student?" (2021, 22). The point of their Scholarship of Teaching and Learning (SoTL) research transcended Ahmed's research. Ahmed has not published on teaching and learning, andragogy and the curriculum. It is the work of universities that remains most undertheorized by Ahmed. It is the work of universities that remains the focus of this article.

\section{Quit Lit (where Tara probes the privilege of walking away from an academic job)}

Sara Ahmed blogged about her resignation from Goldsmiths University. These blogs are part of a genre, that has a long history but intensified after the Global Financial Crisis and the radical restructures that swept through universities. Academics who rarely had to teach suddenly gained accountable workloads that were transparent through a department, school or faculty.

Quit Lit became the genre label granted to journalistic articles or blogs that explained why a dummy spit was required to resign from an organization. A subgenre of Quit Lit, that is less pejorative and more neoliberal, is the entrepreneurial journey to self-discovery. The archetype is Katie Taylor's post on LinkedIn (obviously). Titled "Why I quit academia to start a consulting business," the narrative is clear.

It wasn't because I lacked amazing opportunities for collaboration in a discipline I had fallen in love with years before. It wasn't because I wished for more amazing colleagues or more engagement from students. It wasn't because of outrageous expectations from my department or lack of support to accomplish the expectations of tenure. And it wasn't' so much for personal reasons either, as I had the unthinkable luck of landing a tenure-track job in the same city where my $\mathrm{PhD}$ husband found work he loved in the field of chemistry AND where my dissertation research took place AND where all my immediate family lives (2017).

At least Katie Taylor is aware of the gift she was granted, and the time and money spent to hire her, and the loss of that opportunity to other well-qualified academics. Yet the reason for this professional suicide must be read to be believed.

The forces that pulled me away from academia and towards life as an entrepreneur and small business owner took me by surprise and delight. The universe's calling for me to become a writing consultant - one who works with clients outside of academia at that - resounded softly at first, with a few neat client projects, and then grew louder over time as my professional identity expanded beyond the walls of the classroom (Taylor 2017)

Two points. Firstly, when justifying a life decision by confirming "the universe's calling" is about as likely as answering the telephone and Elvis is on the line. Secondly, the idea that she chose this time in academic history - where entrepreneurship, impact and engagement with diverse communities is so 
welcomed in universities - is odd. At the very point that academics needed to be entrepreneurial, she left academia to be an entrepreneur.

Another sub-genre of Quit Lit is the dummy spit. Best captured in the pages of the Times Higher Education - obviously - Ellen Kirkpatrick embodies this mode of resignation. Her article, titled "The academy I dreamed of for 20 years no longer exists, and I am waking up" (2019) captures the dummy spit with great relish. Kirkpatrick had finished her doctorate and made this decision 18 months after the viva. She was unable to gain stable work. Teaching was difficult. There was little space for 'passion projects' in research. Academics were micromanaged. She is accurate in all of these determinations. But academics are not alone. Work is hard - everywhere. Why should academics be special, or chosen, or protected? We have the gift of an education. Our task is to serve the society that gave us that gift. But we have the right to earn a living and be paid for our work. Significantly though, Kirkpatrick did recoil from the phrase 'Quit Lit.'

Indeed, I do not know one person with a PhD who is a quitter. That is why, despite the ring to it, 'quit lit' is such a band descriptor of the burgeoning genre of articles written by academics leaving the profession. It has strong whiff of voluntarism about it, placing the responsibility of the 'decision' to leave squarely with those doing the leaving. People are leaving academic not because they are quitters but because the system is broken. Their stories are more than just plaintive shouts into the wind: they are reminders and invitations. If we must coin a rhyming new genre, let's call it exist lit (2019).

Absolutely, international higher education is broken. The reason for this break is that the purpose of a university is unclear. It has been covered in the muck of employability, research and development for industries requiring maximum results for minimum resourcing, and metrics appropriate to very few disciplines being generalized to all. But is the solution to leave? Did Kirkpatrick 'leave' academic life, or did academic life leave her? That is a key question. Why there is so much agitation around 'Quit Lit' is that all academics are under pressure. Some have chosen to remain to try and keep the Titanic Universities afloat, at least buoyant until they can be revisioned with new meaning. But secondly, most academics cannot afford to 'leave' academic. It is a job. Academics are workers. The capacity to decide to leave is based on the assumption that rent, food and the needs of a family can be funded from alternative funding pathways. The only thing worse than being exploited is not being exploited. Bills have to be paid. The capacity to quit is a privilege. This privilege is only intensified when it is logged and extemporized on the way out of the building.

Sara Ahmed held permanent positions in elite universities. She received grants, research leave and was published by elite US-based university publishers. From this context, she investigated injustice. Certainly, she has experienced racism, sexism and discrimination. But we - as scholars - are accountable for the decisions we make. She chose to work in elite institutions, rather than in universities confronting multilayered injustice in disempowered towns and cities. She chose elite university publishers, rather than independent publishers. She chose to leave when a sexual harassment claim was mis-handled, rather that stay, fight and leverage into positions of leadership to make a difference. 
It is very tough to be a leader in difficult times for higher education. While alt-ac pathways are important and emerging, it is a disrespect of the future of our universities to walk away rather than double down, recommit, engage, and create change. The capacity to walk away from a well-paid job is a gift that few possess. It is a position of privilege. In perhaps the most moving of the anti-quit-litters, Caroline Hagood stated that, "there's something meaningful about a calling: a life of creative-intellectual service that impresses nobody but you" (2019). She offered a rendering of her working life:

the work of being a small press editor, no matter how storied the history of this press might be, the work of being an adjunct, the work of being a small press author, the work of being a parent ... I do treasure the work I do. I savor helping to foster and disseminate the writing of underrepresented students and writers, creating my own under-read books, and bringing up my charming little monsters. I feel proud of my students and proud of the work I do (2019).

Sara Ahmed made "resignation ... a feminist issue" (2016). She was - rightly - disgusted about the abuse of power by academics over students. These relationships can never really be consensual. The power differential is too great. She was right to question poor policies and procedures when managing these complaints. But it is important to recognize that deep and profound changes have been made. The Respect. Now. Always. Report in Australia (Universities Australia 2016) demanded changes and required reporting to government. But further, opting out of this issue was no longer possible. Indeed, the former Vice Chancellor of Ahmed's former institution, the University of Adelaide, was removed from his post for sexual harassment. The legacy charges at his former universities were revealed and the Independent Commission Against Corruption (ICAC) conducted an investigation with recommendations for the University. Ahmed described that resigning in feminist protest "does get attention" (2016). The challenge is that when a senior feminist leaves an organization, a senior feminist leaves an organization. What is required is for senior feminists to remain in institutions and for sexual predators to leave. That happens with strong regulation and governance, rather than Quit Lit. This is not a matter of a feminist gaining attention. It is about leadership being shaped by feminism. We now move to Aidan's section, to explore why this context requires courage, grit, persistence, and commitment. And a Reading Group.

\section{Reading in Context (Aidan returns to neoliberalism as a context for reading)}

Higher education is in an increasingly troubling time. Its brushes against neoliberal capitalism, its degeneration into managerialism and its embrace of political corruption at the highest levels place it in increasing jeopardy (Ball, 2012; Brabazon, 2020; Connell, 2019; Giroux, 2014; Marginson, 2011). The tenuous connection between higher education and its students needs is waning and requires novel approaches to fix the issues facing late capitalist society (Afonso, 2013; Cornelius-Bell \& Bell, 2020; Rao et al., 2021; Slaughter \& Leslie, 1997). In particular, academic pathways for the humanities and social sciences where students are stretched and have the ability to communicate across discipline bounds are at serious risk in a climate of output measurement, KPIs and increasing pressure for funding (Brabazon, 2016b; Brett, 2021; Cornelius-Bell \& Bell, 2020). Doctoral education is on dangerous ground with students and academics increasingly exploited and their roles redefined, there is a serious need for opportunities to enhance, stretch and communicate. It is in this complex and moving context that the COVID-19 global health crisis entered and with it an acceleration of the problems, new challenges, and 
some victories for universities emerged (Adnan, 2020; Aristovnik et al., 2020; Churchill, 2020; Drane et al., 2020). The sudden move online proved challenging, particularly for disadvantaged students, and the community of higher education was substantially disrupted globally as health conditions slid (Aristovnik et al., 2020; Pather et al., 2020). In the humanities and social sciences, for doctoral students, this disruption heralded the end of scholarly community in face-to-face modality, instead requiring alongside their coursework colleagues a rapid move online. Supervision was disrupted from its normal forms, wondering into supervisor's offices to discuss ideas was no longer a possibility, instead a new community of online praxis began to form. While in our context in Adelaide in Australia, we have been relatively fortunate with COVID-19 cases, enduring only two substantive lockdowns, the learning about the possibilities of global communities in doctoral education left an impact on our thinking. This article has explored the relationship between international community which sprung up around our well-connected supervisors' advertising of our reading group, explores some of the work of Sarah Ahmed, and renders a scholarly critique of the current state of doctoral education and the interface with reading scholarly texts.

The surreal experience of being surrounded by smart people through the digital ether cannot be paralleled, even conferences which draw together diverse scholars and schools of thought cannot contend with the power of the online meeting. When Tara established the seminar series on Sarah Ahmed's work, I was surprised. There was a novelty to the idea of focussing intensively on a single scholar's body of work across their lives. Indeed, reading Ahmed's work from beginning to end offered great insight into how she presents her work, her writing style, methodological concerns, and epistemological perspective. This was a period of deep learning for me, as I had quite minimal engagement with the highly theoretical feminist space. I am sure some will be quick to conclude that a white male appearing person who has minimal engagement in this space was some kind of luddite, or perhaps worse a 'brocialist.' The bulk of my studies in feminism had largely been Marxist informed, as is much of my own scholarship. Of course, indeed, Marxist feminism has suffered many critiques itself, and orthodox Marxism is certainly lacking when it comes to unpacking and prioritising women's rights. Regardless, I was pleased to learn what felt like alongside Ahmed as her theoretical perspective shifted. This change and growth are truly a special part of doctoral education and something all good reading, writing and thinking should do - or perhaps all readers, writers and thinkers should do. The real surprise, then, to me was when the global pool of doctoral students arrived in the reading group. A truly diverse cluster of students and scholars from across the globe. Strangely, many of these appeared to be people who were happy to talk without reading. As a casualised tutor, one of my favourite recurring jokes is to jump on the band wagon with first year students about "doing the reading" - something many tutors struggle with. Here, at a global doctoral level we were to suffer those who had not engaged with the 'prescribed text' for the week perhaps even beyond the title.

An intellectual discussion? Not so. Many remained silent, listening and watching to the event unfold, yet others were quick to add their perspectives, even when these deviated from the content of the books under discussion. Interestingly, there was a quick reaction towards a defence of Ahmed's work, a gritting of teeth and a swelling of anger at the thought of her work suffering scholarly critique. Instead of engaging with the work as it was appreciating the living growing knowledge and scholarship of the author herself it was as though an infallible academic celebrity was being placed on public trial by an online reading group. Defenders were assembled, and this defence required a slippage from the research to the researcher. Fortunately, through Tara's skilful mediation, the discussions never became overtly heated. The 
phenomenon of angst about and defence of a member of the academic community, however, recurred as a theme throughout - a world of questions flooded to my mind. Was this the academic celebrity that I had initially ascribed to limited in the 'intellectual' figures of the alt-right? Are students globally engaging with reading materials at a deep level in the same way we do? What ideas and politics are being captured here that draw such anger and defence? The broad scope of questions largely remained unanswered as slowly, across each week of the seminar series the unread disappeared.

When knowledgeable scholars gather, read or otherwise, a set of skills assemble. Those who are not overly opinionated are happy to analyse themselves as a subject in an analytical thought experiment, relating their understanding to the subject of conversation often in meaningful ways. Here, I suspect, our seminar series flourished. By gathering a plurality of perspectives and diverse 'identities' we had assembled smart, analytical people - people who had many experiences, particularly of academia. With much of Ahmed's work centring on/in the work of the academy, this parallel experience gave great insight into the landscape of global higher education. Rather than a movement into cherry picked ideas, emotive outburst, and downright slander, our group lifted. Each week a challenge to culture, institutions and the problems of the world. However, the problems of doctoral education cannot be ignored - in a world of increasing online supervision, social isolation, and a method/theory/methodology divide there is a need to engage with original theoretical and methodological material, even when it does not agree with you. Here problems arise, rather than learning from extant theory, new conversations emerge in a medley of methodological perspectives - interesting, but intellectually robust? In extreme cases the divisive and singular focus in the humanities and social sciences on 'single issue' theories create immense trouble for disciplines and students. This alignment of academia with identity politics (Hobsbawm, 1996) is as dangerous as political extremism. To elaborate, this a deviation through the purpose and nature of our institutions is required, a broad question of governance and purposes of 'academics' and scholars in late modernity looms over the humanities and social sciences in an age of 'job ready graduates' (Brett, 2021; Daly \& Lewis, 2020).

Universities are old institutions, structures of studying, working and producing intellectual labour. In Australia, these institutions are colonial, young and prone to corruption, systemic disruption and massive change. Globally, the institution's age has not prevented the creep of neoliberal capitalism, the corruption of theory and practice, and the acceleration of fundamental abandonment of basic functionality (Brown, 2015; Marginson, 1999; Slaughter \& Leslie, 1997). In their originary form, if we take institutions as designed for the scholarly activity of intelligent people - admitting that those people are frequently privileged, and historically white, male, and ruling class - we can see universities as a home for some people to conduct intellectual labour in particular forms. While higher education has been subject to frequent disruption, the humanities and social sciences have long been the home of critique and robust debate over scholarship, theory and practice. Even when subject to its due critique of ivory tower syndrome, academia's social sciences have remained fundamentally connected to culture. With the 1960s radical student movements, these structures adapted to give students a more liberal position in the academy (Cornelius-Bell \& Bell, 2020; Jones, 1969), and in subsequent years the boom of student numbers only increased places for students in the humanities and social sciences, often disproportionately to those in STEMM (Croucher et al., 2013; Forsyth, 2014, 2020). Here the humanities and social sciences are poised to provide a robust education to a broad spectrum of human subjects, those who will become the voters, thinkers and leaders - and who are more often women. This is a space which could be harnessed to teach 
robust methodology, theory and practice, but instead it is often relegated to teaching students of the other disciplines how to write. Indeed, rather than an alignment to the core purpose of the humanities and social sciences - understanding and investigating society and culture and creating capable thinking citizenry- the universities prefer a skills focus. Moreover, those in the social sciences frequently teach a simpler curriculum to students who are frequently ill-prepared for rigorous debate, lengthy reading and fulsome engagement - to a point now where academia is contorting itself into a technical education. Worse still, in many instances, this has reached the level of doctoral education. Rapidly, particularly in those less aligned with the 'old school' humanities and social sciences, such as the discipline of education, a methodology as tomato sauce approach emerges. In this space, rather than starting from a theoretically informed wellread methodological space, data are collected and theory is poured on top to meet the requirements of doctoral education or a journal's methodological imperative. The tomato saucing of theory capitulates good practice into the kitchen waste of scholarship. Rather than robust critical engagement with the world, an increasingly technician-focussed education emerges. Both here and in the social sciences we face those students who are informed by a deep connection to identity politics, whose tutors and lecturers prefer an easy 'education' over a methodological robustness, and a university sector swaying in the breeze of ideological change and 'corporate capture' (Bonnell, 2016). A grim depiction, though one which held resonance for our seminar series - as the periphery of global scholars came and went without critically engaging with the texts of the group.

Academia is breeding divisive politics, acritical pop theoreticians, and anti-unitary messaging for the humans of the university. Regardless of political alignment, the nature of universities is to prepare people for the world around them, all education, formal or otherwise, must be harnessed to create better thinkers, actors and creators in all facets of life, this is fundamentally a unitary project. Bringing people together to encourage critical thought about the world around them - from the biology laboratory to the humanities reading room. Rather than nurturing a divisive politic, academia should be playing a critical role in the praxis of producing critical thinkers. Rather than pop theory, deep, real understandings of ontoepistemological worlds should be at the forefront. Recounting what should be done does little for the advancement of the academy, particularly in the face of what challenges it - government agendas which see the institution as a place of labour force production. In this challenging context, doctoral education is the last bastion of critical engagement with society, particularly for the humanities and the social sciences. I am not here to deliver grim tidings, a slow death of cultural studies, or indeed to offer disturbing metaphors about tomato source. Instead, from our seminar series quality and connection arose.

In a post/COVID world, when connection and feeling become invisible or impossible, and the economy takes centre stage over the value of human life, it is easy to slide into dark positions on the world. However, it is still possible to find gems of practice and thought. By the later period of our seminar series, the attendance had waned, but the core of passionate, well read and intelligent people remained. Drawing hope from robust discussion, contributing novel experience and understanding, and connecting with the power and interpretation of words in Ahmed's work we forged new collective understandings. For me, accepting that Marxist method (theory and practice) are at the forefront of mind, a bringing together of perspectives - the postmodern and the orthodox - created a glimpse into the thinking on the other side of the theoretical divide - a uniquely powerful moment of understanding and acceptance of the diverse perspectives of academia, and a mutual respect amongst the groups' members as we pondered difficult 
questions. Friendship and cross-boundary understandings of the need for unitary progress, reconfigurations of the darkening world, and a new bright future emerged. In our final discussion, an in depth conversation about the academic precariat (O'Connor, 2020; Standing, 2014) created feelings of a united need for a revitalising of high quality education, employment stability, and the end to exploitative work in the academy. Further to this, a revisioning of the values of what it means to be an academic worker, scholar and thinker in late modernity arose, and a question of 'what's the use' (Ahmed, 2019) of a PhD in 2021, succinctly analysed and summarised by Elisa: "to produce this document and then you become a doctor, but it's more about the skills that you learn - so I think that the PhD process teaches you a way of interacting with information, an approach to intellectual curiosity ... it's about levelling up your thinking game." - This is a hopeful position for conversation about the academy, and a strong space to create thinkers, learners and communities that value critical and creative thinking and input. There is hope in academia, as 'younger' scholars move in new energy emerges - with stewardship from the experienced, and with a partnered attitude to development of understanding and skills the $\mathrm{PhD}$, and ultimately the future of undergraduate education, are in good hands. The future just needs to be realised and supported - and more multi-disciplinary and clear-headed thinking is needed to draw global perspectives together. The power of the Zoom meeting in a post/COVID world will not falter, we just need to realise the peoplepowered dream of robust academic critique and high-quality citizenship.

\section{Digital Legacy (from an analogue dean)}

I never question the gift of education. I have taught and researched through my career. The dialogue between these functions is powerful and productive. I have worked for dodgy deans, disturbing and ruthless vice chancellors, and brutalizing senior academics. But I have never doubted the value and power of research and teaching. COVID-19 has been horrific. It has also been a gift as students reminded us why reading matters, thinking matters and - yes - community matters.

Much of international higher education operates against the building of a community. Indeed, the celebrity intellectual fetishizes and individual over the community-building imperatives of teaching and research. Indeed, Crawford Spence argued that, "dominant modes of managing teaching and research in Higher Education Institutions produce significantly dysfunctional effects" $(2019,761)$. Spence, from a post at King's College London, argues that a judgement of quality is more important than measurement of quality. Certainly, metrics are inelegant and frequently flawed proxies. But the subjectivities invested in judgements of quality are saturated with class-based biases and assumptions. Judgements of quality fuel gatekeeper cultures which reinforce the status quo in disciplines and knowledge. The greater question is how contemporary academics attempt to preserve any semblance of the university system for the students that follow us and are able to - even from precariat employment - join our global reading community.

This experiment in Covid-19 internationalization of ideas was successful. But it was surprising. My initial assumptions that students were not reading proved to be accurate. Indeed, students joined a reading group without having completed the reading. Knowing about the celebrity intellectual's personal story through blogs was sufficient expertise for entry into this space. Yet as the weeks progressed, the fans left the group, and the readers remained. Through this shared consciousness and experience, friendships were created, confidences shared, and tough political debates were probed. 
Because of digitization, the recordings of this odd, extraordinary time were captured. We have a record of the complexities of Celebrity Intellectuals, the challenges of (non)reading in a reading group, and a snapshot of future scholars grappling with instability, fear, shortages, and a loss of intellectual purpose.

Seminar 1 - https://youtu.be/NroN_MskrVo

Seminar 2 - https://youtu.be/duzYPKqygQk

Seminar 3 - https://youtu.be/tAQ1v1SseTI

Seminar 4 - https://youtu.be/1xoDi8QZe5w

Seminar 5 - https://youtu.be/3z5Jpx5culE

Seminar 6 - https://youtu.be/XaTs3Bdxm5w

Seminar 7 - https://youtu.be/cKDbkCQPZsM

Seminar 8 - https://youtu.be/5upVA0TvWEI

Seminar 9 - https://youtu.be/1TsbWLMOxkc

Each of these seminars offered poignant micro-histories of the precariat workforce, building connections, communication and community is unusual places. These seminars also reveal the fans of a celebrity intellectual, that had not read her work. They were fans of a person, not a peer probing the words written by this scholar. But I also note that during these nine remarkable weeks, something happened. That 'something' did not involve Sara Ahmed or her books. It involved scholars meeting, sharing, and developing ideas. This session started as a reading group. It concluded as a community of scholars. It is remarkable to watch how a community from around the world was created. In tough times, ideas matter. Reading matters. But community matters more.

\section{References}

Adnan, M. (2020). Online learning amid the COVID-19 pandemic: Student's perspectives. Journal of Pedagogical Research, 1(2), 45-51. https://doi.org/10.33902/JPSP.2020261309

Afonso, A. (2013, December 11). How Academia Resembles a Drug Gang. Impact of Social Sciences. https://blogs.lse.ac.uk/impactofsocialsciences/2013/12/11/how-academia-resembles-a-druggang/

Ahmed, S. (1998). Differences that matter. Cambridge University Press.

Ahmed, S. (2000). Strange encounters: Embodied others in Post-coloniality. Routledge.

Ahmed, S. (2004). The cultural politics of emotion. Edinburgh University Press.

Ahmed, S. (2006). Queer phenomenology. Duke University Press.

Ahmed, S. (2010). The Promise of Happiness: Duke University Press.

Ahmed, S. (2012). On being included. Duke University Press.

Ahmed, S. (2014). Wilful subjects. Duke University Press.

Ahmed, S. (2016). Resignation is a feminist issue. Feministkilljoys.

https://feministkilljoys.com/2016/08/27/resignation-is-a-feminist-issue/ 
Ahmed, S. (2017a). Curriculum Vitae. https://static1.squarespace.com/static/58ad660603596eec00ce71a3/t/58b36dc346c3c45d74e9a01 c/1488154054765/CV.pdf

Ahmed, S. (2017b). Living a feminist life. Duke University Press.

Ahmed, S. (2019). What's the use? On the uses of use. Duke University Press.

Allen, H., Barrall, A., Vincent, K., Arria, A., (2020). Stress and burnout among graduate students: moderation by sleep duration and quality. International Journal of Behavioral Medicine, 28, 2128. https://doi.org/10.1007/s12529-020-09867-8

Arum, R., \& Roksa, J. (2011a). Academically adrift: Limited learning on college campuses. Chicago: University of Chicago Press.

Arum, R. \& Roksa, J., (2011b). College, too easy for its own good. Los Angeles Times. June 2: http://www.latimes.com/news/opinion/commentary/la-oe-arum-college20110602,0,1981136.story

Aristovnik, A., Keržič, D., Ravšelj, D., Tomaževič, N., \& Umek, L. (2020). Impacts of the COVID-19 pandemic on life of higher education students: A global perspective. Sustainability, 12(20), 8438. https://doi.org/10.3390/su12208438

Ball, S. J. (2012). Performativity, commodification and commitment: An I-spy guide to the neoliberal university. British Journal of Educational Studies, 60(1), 17-28.

Blyth, S. (2013). Austerity: The history of a dangerous idea. Oxford: Oxford University Press.

Bonnell, A. G. (2016). Democratisation or management and corporate capture? Theses on the governance crisis of Australia's semi-privatised public universities. Australian Universities' Review, The, 58(2), 26-32.

Brabazon, T. (2002). Digital Hemlock. Sydney: University of New South Wales Press.

Brabazon, T. (2008). The University of Google. Aldershot: Ashgate.

Brabazon, T. (2013). Digital dieting. Aldershot: Ashgate.

Brabazon, T. (2016a) Imposter Syndrome. Office of Graduate Research Flinders University, April 14: https://www.youtube.com/watch?v=6I9pIqjtnKo

Brabazon, T. (2016b). Winter is Coming: Doctoral Supervision in the Neoliberal University. International Journal of Social Sciences \& Educational Studies, 3(1), 14-34.

Brabazon, T. (2020). From bad apples to zombies? Walking dead leadership in the contemporary university. Fast Capitalism, 17(2), Article 2. https://doi.org/10.32855/fcapital.202002.009

Brabazon, T., Quinton, J., Hunter, N. (2020). Panic learning. Fast Capitalism, 17(2), https://fastcapitalism.journal.library.uta.edu/index.php/fastcapitalism/article/view/385/478

Brabazon, T., Redhead, S., Chivaura, R. (2018). Trump Studies. Bingley. Emerald.

Brabazon, T. Connections and Community. (2021) Brabazon.net. http://brabazon.net/2021/03/27/connections-and-community/

Brett, J. (2021, March 1). The bin fire of the humanities. The Monthly. https://www.themonthly.com.au/issue/2021/march/1614517200/judith-brett/bin-fire-humanities

Brown, W. (2015). Undoing the demos: Neoliberalism's stealth revolution (First Edition). Zone Books.

Crain, C. (2018). Why we don't read, revisited. New Yorker. June 14. https://www.newyorker.com/culture/cultural-comment/why-we-dont-read-revisited

Churchill, B. (2020). COVID-19 and the immediate impact on young people and employment in Australia: A gendered analysis. Gender, Work \& Organization, 1-12. https://doi.org/10.1111/gwao.12563

Connell, R. (2019). The good university. Monash University Press.

Cornelius-Bell, A., \& Bell, P. (2020). Partnership as student power: Democracy and governance in a neoliberal university. Radical Teacher, 118(1). https://doi.org/10.5195/rt.2020.797

Croucher, G., Marginson, S., Norton, A., \& Wells, J. (Eds.). (2013). The Dawkins revolution: 25 years on. Melbourne University Press. 
Daly, A., \& Lewis, P. (2020). The Proposed Job-ready Graduate Package: A misguided arrow missing its target. 23(2), 21.

Damiano, S. (2019). Why reading is such a good workout for the brain. May 9. https://www.thehealthy.com/aging/mind-memory/why-reading-is-important/

Drane, C., Vernon, L., \& O'Shea, S. (2020). The impact of 'learning at home' on the educational outcomes of vulnerable children in Australia during the COVID-19 pandemic (pp. 1-17) [Literature Review]. Curtin University.

Elliott, J. and Attridge, D. (eds) (2011). Theory after Astride 'theory'. London. Routledge.

Forsyth, H. (2014). A history of the modern Australian University. NewSouth.

Forsyth, H. (2020). From progressive pedagogy to 'capitalist fodder': The new universities in Australia. In Utopian Universities: A global history of the new campuses of the 1960s (pp. 305-322). Bloomsbury Publishing Plc.

Gadsby, S. (2021). Imposter syndrome and self-deception. Australasian Journal of Philosophy, 1-15. doi:10.1080/00048402.2021.1874445

Giroux, H. A. (2014). Neoliberalism's war on higher education. Haymarket Books.

Greener, S. (2021). Non-supervisory support for doctoral students in business and management: a critical friend. The International Journal of Management Education, 19. https://doi.org/10.1016/ijme.2021.1004463

Grey, C., \& Sinclair, A. (2006). Writing differently. Organization, 13(3), 443-453.

Gurcan, E., \& Kahraman, O. (2020). COVID-19 in historical perspective: How Disaster capitalism fabricates a fear-managed world order? Briq, 1(3), 49-62.

Hagood, C. (2019). On 'Quit Lit' and why I won't be quitting any time soon. Kenyon Review Blog: https://kenyonreview.org/2019/10/on-quit-lit-and-why-i-wont-be-quitting-any-time-soon/

Hart, C., \& Colonna, S. (2021) Feminist space invaders: Killjoy conversations in neoliberal universities. 119: $21-29$

Hobsbawm, E. (1996). Identity politics and the left. New Left Review, I (217), 10.

Hayot, E. (2014). Academic writing, I love you. Really, I do. Critical Inquiry, 41(1), 53-77.

Heinze, R. (2015). "This Makes No Sense at All”: Heterarchy in Fictional Universes. Storyworlds. A Journal of Narrative Studies, 7(2), 75-91.

Hyatt, M. (2020). 5 Ways reading makes you a better leader: the science behind reading and influence. Michael Hyatt.com, https://michaelhyatt.com/science-readers-leaders/

Hyland, K. (2002). Options of identity in academic writing. ELT Journal, 56(4), 351-358. doi:10.1093/elt/56.4.351

JISC. (2007). Information behaviour of the researcher of the future. CIBER briefing paper. UCL, http://www.jisc.ac.uk/media/documents/programmes/reppres/gg_final_keynote_11012008.pdf

Jones, G. S. (1969). The meaning of the student revolt. In A. Cockburn \& R. Blackburn, Student power: problems, diagnosis, action. Penguin.

Kiriakos, C. M., \& Tienari, J. (2018). Academic writing as love. Management Learning, 49(3), 263-277. doi:10.1177/1350507617753560

Levine, F.J., Nasir, N.S., Rios-Aguilar, C., Gildersleeve, R.E., Rosich, K.J., Bang, M., Bell, N.E., \& Holsapple, M.A. (2021). Voices from the field: The impact of COVID-19 on early career scholars and doctoral students. American Educational Research Association; Spencer Foundation, https://doi.org/10.3102/aera20211

Marginson, S. (2011). Higher education and public good: higher education and public good. Higher Education Quarterly, 65(4), 411-433. https://doi.org/10.1111/j.1468-2273.2011.00496.x

Marginson, S. (1999). The Enterprise University comes to Australia. 1-17.

Mirowski, P. (2003). Never let a good crisis go to waste: how neo-liberalism survived the financial meltdown. New York: Verso. 
O'Connor, S. (2020, December 1). The academic precariat deserves better. Financial Times. https://www.ft.com/content/3302681d-cfb7-4aed-9629-5e9b467e83df

Pather, N., Blyth, P., Chapman, J. A., Dayal, M. R., Flack, N. A. M. S., Fogg, Q. A., Green, Hulme, R. A. K., Johnson, I. P., Meyer, A. J., Morley, J. W., Shortland, P. J., Štrkalj, G., Štrkalj, M., Valter, K., Webb, A. L., Woodley, S. J., \& Lazarus, M. D. (2020). Forced disruption of anatomy education in Australia and New Zealand: An acute response to the covid-19 pandemic. Anatomical sciences education, 13(3), 284-300. https://doi.org/10.1002/ase.1968

Parks, L., \& Walker, J. (2020). Disaster Media: Ending the curve of ecological disruption and moving toward social justice. Media + Environment. 1(2): https://mediaenviron.org/article/13474disaster-media-bending-the-curve-of-ecological-disruption-and-moving-toward-social-justice

Pervez, A., Brady, L., Mullane, K., Lo, K., Bennett, A., Nelson, T. (2021). An empirical investigation of mental illness, impostor syndrome, and social support in management doctoral programs. Journal of Management Education, 45(1), 126-158.

Philosophy Football. (2021). Jean Baudrillard. https://www.philosophyfootball.com/philosophers/-jeanbaudrillard.html

Pittam, G., Elander, J., Lusher, J., Fox, P., \& Payne, N. (2009). Student beliefs and attitudes about authorial identity in academic writing. Studies in Higher Education, 34(2), 153-170. doi:10.1080/03075070802528270

Potter, A. (2010). The authenticity hoax: How we get lost finding ourselves. New York: Harper Collins. Pullen, A., \& Rhodes, C. (2015). Writing, the feminine and organization. In: Wiley Online Library.

Rao, N., Hosein, A., \& Raaper, R. (2021). Doctoral students navigating the borderlands of academic teaching in an era of precarity. Teaching in Higher Education, 1-17. https://doi.org/10.1080/13562517.2021.1892058

Slaughter, S., \& Leslie, L. L. (1997). Academic capitalism: Politics, policies, and the entrepreneurial university. Johns Hopkins University Press.

Spence, C. (2019). Judgement versus metrics in higher education management. Higher Education, 77, 761-775.

Standing, G. (2014). The Precariat. Contexts, 13(4), 10-12. https://doi.org/10.1177/1536504214558209

Taylor, K. (2017). Why I quit academia to start a consulting business. LinkedIn. https://www.linkedin.com/pulse/why-i-quit-perfect-academic-job-start-consulting-trauth-taylor/

Taylor, Y., \& Breeze, M. (2020). All imposters in the university? Striking (out) claims on academic Twitter. Women's Studies International Forum, 81, 102367. doi:https://doi.org/10.1016/j.wsif.2020.102367

Tett, G., (2009). Fool's Gold: How unrestrained greed corrupted a dream, shattered global markets and unleashed a catastrophe, London: Little Brown.

Universities Australia, (2016). Respect. Now. Always. https://www.universitiesaustralia.edu.au/project/respect-now-always/ 